\title{
Introduction to the Minitrack on Global, International, and Cross-Cultural Issues in the Digital Economy
}

\author{
Barbara Krumay \\ Johannes Kepler University Linz \\ barbara.krumay@jku.at
}

\author{
Edward W.N. Bernroider \\ Vienna University of Economics \\ and Business (WU) \\ edward.bernroider@wu.ac.at
}

\author{
Pnina Fichman \\ Indiana University \\ fichman@indiana.edu
}

Globalization has historically been tied to technological innovation, and the present era of the digital economy is no different. The worldwide spread of interconnected information and communication technologies (ICTs) has provided the infrastructure for multinational businesses, created new cultural connections irrespective of geographic boundaries and distances, and allowed an increasingly mobile global population to be connected to their friends, families, and cultures no matter where they are. Businesses across all sectors have been updating their business models to reap benefits from the advances in ICTs, which allowed many to extend their reach into global and international markets, and thus also into different cultural contexts.

In line with the track recognition that the Internet and the digital economy have transformed the way we work, learn, and play, our minitrack focuses on the sociotechnical dynamics and the ways in which the
Internet and the digital economy affect people, groups, organizations, and societies. We are in particular interested in the impact of global, international, and cross-cultural issues on the provision, use and also control of ICTs across the globe.

The paper accepted Designing for Cultural Values: Towards a Theory-motivated Method for Culturesensitive Adaptation of Information Systems, by Andreas Janson, Ernestine Dickhaut and Matthias Soellner perfectly covers the topic of the minitrack. It addresses the challenges evolving from non-acceptance of information systems (IS) due to cultural values of individuals. Based on a design science research (DSR) approach and drawing from IT-culture conflict theory, a method for culturesensitive IS adaptation has been developed and evaluated. Thus, this paper aims at contributing to the exploration of culture in IS development but also to provide guidance regarding IS acceptance for specific target groups. 